\title{
Identifying and Understanding Communities Using Twitter to Connect About Depression: Cross-Sectional Study
}

Amber D DeJohn¹, BA; Emily English Schulz²; Amber L Pearson ${ }^{1}$, PhD; E Megan Lachmar², MS; Andrea K Wittenborn ${ }^{2,3}, \mathrm{PhD}$

\footnotetext{
${ }^{1}$ Department of Geography, Environment, and Spatial Sciences, Michigan State University, East Lansing, MI, United States

${ }^{2}$ Department of Human Development and Family Studies, Michigan State University, East Lansing, MI, United States

${ }^{3}$ Division of Psychiatry and Behavioral Medicine, Michigan State University, Grand Rapids, MI, United States
}

\section{Corresponding Author:}

Amber L Pearson, PhD

Department of Geography, Environment, and Spatial Sciences

Michigan State University

Geography Building

673 Auditorium Road

East Lansing, MI, 48824

United States

Phone: 15173554649

Fax: 15174321671

Email: apearson@msu.edu

\section{Abstract}

Background: Depression is the leading cause of diseases globally and is often characterized by a lack of social connection. With the rise of social media, it is seen that Twitter users are seeking Web-based connections for depression.

Objective: This study aimed to identify communities where Twitter users tweeted using the hashtag \#MyDepressionLooksLike to connect about depression. Once identified, we wanted to understand which community characteristics correlated to Twitter users turning to a Web-based community to connect about depression.

Methods: Tweets were collected using NCapture software from May 25 to June 1, 2016 during the Mental Health Month $(n=104)$ in the northeastern United States and Washington DC. After mapping tweets, we used a Poisson multilevel regression model to predict tweets per community (county) offset by the population and adjusted for percent female, percent population aged 15-44 years, percent white, percent below poverty, and percent single-person households. We then compared predicted versus observed counts and calculated tweeting index values (TIVs) to represent undertweeting and overtweeting. Last, we examined trends in community characteristics by TIV using Pearson correlation.

Results: We found significant associations between tweet counts and area-level proportions of females, single-person households, and population aged 15-44 years. TIVs were lower than expected (TIV 1) in eastern, seaboard areas of the study region. There were communities tweeting as expected in the western, inland areas (TIV 2). Counties tweeting more than expected were generally scattered throughout the study region with a small cluster at the base of Maine. When examining community characteristics and overtweeting and undertweeting by county, we observed a clear upward gradient in several types of nonprofits and TIV values. However, we also observed U-shaped relationships for many community factors, suggesting that the same characteristics were correlated with both overtweeting and undertweeting.

Conclusions: Our findings suggest that Web-based communities, rather than replacing physical connection, may complement or serve as proxies for offline social communities, as seen through the consistent correlations between higher levels of tweeting and abundant nonprofits. Future research could expand the spatiotemporal scope to confirm these findings.

(JMIR Ment Health 2018;5(4):e61) doi: 10.2196/mental.9533

\section{KEYWORDS}

depression; Web-based; social connection; Twitter; tweet; online communities 


\section{Introduction}

Each day, 313 million global users share 500 million messages or tweets on the popular social networking site Twitter [1]. Within a 280 character limit, users can type a hashtag followed by a word or phrase to discuss a specific topic, link content about the same topic, or initiate dialogue on a topic. Twitter content is publicly available worldwide, providing valuable data for research, including the topic of mental health [2].

Each year in the United States, about $7 \%$ of adults suffer from depression, but only half seek professional help $[3,4]$. In many communities, mental disorders such as depression carry a social stigma, resulting in further isolation and lack of treatment [5]. Increasingly, individuals with depression are turning to Web-based communities for support [6]. Because Twitter is a popular networking platform, people often turn to it to connect about mental health issues such as depression [2]. In one study, researchers examined depressive symptoms based on the Diagnostic and Statistical Manual of Mental Disorders in tweets and found them characterized by low mood, fatigue, or loss of energy and problems with the social environment [7,8]. In another study examining the same hashtag as this study, \#MyDepressionLooksLike, researchers found that the content of tweets included themes such as dysfunctional thinking, lifestyle challenges, social struggles, apathy and sadness, suicidal thoughts and behaviors, and seeking relief from depression [2].

Other research has focused on why users communicate about mental health through Web-based communities like Twitter. For example, the study \#WhyWeTweetMH resulted in several themes for tweeting about mental health, including a sense of community, raising awareness, combating stigma, a space for expression, and coping and empowerment [9]. In a study by Park et al (2012) of about 20,000 tweets from approximately 15,000 users regarding depression, results revealed higher levels of tweets about users' own depressive feelings or symptoms as opposed to comments on treatments or others' symptoms [10]. A study from South Korea found that Twitter users who are not depressed view Twitter as a place to share information, whereas depressed Twitter users view it as a site meant for social awareness and emotional interaction [11]. Twitter users with depression "followed," or subscribed to, other users who posted about emotional and everyday life activities; they found it uplifting to read other peoples' positive tweets and reading about others' depression caused them to feel less isolated [11]. However, other research reveals that use of social media can exacerbate mental health symptoms such as depression because of constant social comparison, bullying, suicide contagion, and other aspects [12-15]. While prior research has provided insight into individual-level predictors of seeking connection about depression on social media, less is known about community-level factors.

Possibly, lack of neighborhood amenities, such as parks and museums, may indicate fewer destinations for social interaction between residents. In this way, social bonds may be influenced by a neighborhood's structural and functional characteristics [16]. Lack of amenities may also increase stress among residents who must exert extra effort to gain access to these resources [16]. Poorer neighborhoods may have lower levels of trust between neighbors and lower social support, in part because of blighted conditions in the built environment [16]. In fact, evidence suggests that signs of physical disorder (eg, vacant homes) can lead to feelings of hopelessness and diminish social relationships [17]. Weich et al found that depression was higher among people living in neighborhoods with an abundance of vacant lots and fewer amenities such as gardens and local shops [18].

Lack of neighborhood amenities and thus limited social interactions may be factors that influence use of Twitter for seeking connection about depression. To explore community characteristics that may lead to higher numbers of Twitter users seeking Web-based support, this study employed spatial data to understand how built and demographic features of communities relate to use of Twitter for depression support. Our findings may inform community efforts to increase social interaction and provide support for residents' mental health. This study provides unique information that has not yet been analyzed by examining geographical location and community amenities in the context of tweets about depression.

\section{Methods}

\section{Ethical Approval}

Our research was determined to be Nonhuman Subjects research by the Michigan State University Institutional Review Board. All researchers involved received ethical training by the same institutional review board.

\section{Twitter Data}

Tweets were downloaded through Twitter's public streaming data [19]. Using NCapture, tweets were identified by the hashtag \#MyDepressionLooksLike (QSR International, Burlington, MA, USA). This hashtag encouraged Twitter users with depression to share their experiences and connect with one another, making it useful in answering our research question.

Twitter restricted data capture to a random sample of $10 \%$ of total tweets from public content, and we compiled it into a database [2]. The temporal window for tweet-capture lasted from May 25 to June 1, 2016 (one week of the Mental Health Month), and tweets were pulled at 10:00 am Eastern Standard Time each weekday. Tweets meeting the following criteria were included: (1) each tweet was an original, not a retweet; (2) only one tweet per user; and (3) tweets with geolocations located within a designated 12-state northeastern study area. Thus, 104 tweets were included for analysis at the county level.

\section{County Demographic Data}

To predict expected tweets by county, we compiled demographic data commonly associated with depression diagnoses. We collected demographic data from the 2010 Census and the American Community Survey 2015 5-year estimates [20,21], including age, gender, race, household status, and percent living in poverty. Depression has been found to be the highest among women, unmarried people, low-income persons, ethnic minorities, and people aged 15-44 years [18,22-28]. Thus, we 
compiled county percentages of single-person households, females, those aged 15-44 years, white population, and those living below the poverty line (see Table 1 for data sources).

\section{Community Characteristics Data}

To understand the relationship between community characteristics and levels of tweeting, we compiled data for characteristics that could provide support, in-person treatment, opportunities for social interaction, or indicators of active community residents. These characteristics included parks or protected open spaces, places of worship, museums, active voter rates, mental health care providers, nonprofit organizations (organized by National Taxonomy of Exempt Entities code), K12 schools, and owner-occupied housing units. Likewise, we compiled data on characteristics that might hinder community support, including vacant housing units. Community characteristic data came from several sources (see Table 1). Rates were generated for most variables per 100,000 total population. K12 school rates were generated per 100,000 school-aged population. Percent of active voters was calculated as the percentage of the adult population actively voting in 2016 .

Nonprofit organizations were sorted into groups by purpose using Stata v11.1 (StataCorp, College Station, TX, USA): health, human services, public and societal benefit, religion, and education. Counts of nonprofit organizations by group, places of worship, mental health care providers, and vacant and owner-occupied housing units were summed by county. A rate per 100,000 population was then calculated. The spatial locations of museums, K12 schools, parks, and county boundaries were mapped using ArcGIS v10.5 (Esri, Redlands, CA, USA) [29]. Counts per county were summed, and then a rate per 100,000 total population was calculated. Park areas (in miles $^{2}$ ) were also calculated in ArcGIS, as a percentage of the county's total land area.

Active voter totals were all from the fourth quarter of 2016. We aggregated active voter counts by county and then divided these counts by the active voter population. We then calculated the percent of active voters. For states that do not report active voter totals, we used that state's voter turnout rate for the 2016 presidential election.

\section{Calculating a Tweeting Index Value}

We assumed that, in theory, community levels of support seeking through Twitter should be predicted by demographic characteristics associated with depression and poor mental health [23,25-28]. Thus, we fitted a regression model to predict county-level tweet counts using those variables. Specifically, our multilevel Poisson regression model with robust SEs included independent predictors commonly associated with depression diagnoses including percent female, percent population aged 15-44 years, percent white, percent single-person households, and percent below poverty line, offset by the county population. The model also accounted for the clustering of counties within states.

Our focal interest was on understanding areas that have higher or lower tweeting than expected. So, after fitting the model, we calculated the difference between observed and expected counts and categorized these residuals into tweeting index value (TIV) tertiles, whereby $1=$ undertweeting, mean -0.37 (SD 0.53); $2=$ tweeting as expected, mean -0.02 (SD 0.01); and $3=$ overtweeting, mean 1.36 (SD 1.55). These TIVs were then used to examine community characteristic trends. 
Table 1. Demographic and community characteristic data sources.

\begin{tabular}{lll}
\hline Variable & Data source & Year \\
\hline Percent aged 15-44 years & US Census Bureau & 2010 \\
Percent female & US Census Bureau & 2010 \\
Percent white & US Census Bureau & 2010 \\
Percent single-person household & US Census Bureau & 2010 \\
Percent below the poverty line & US Census Bureau (American Community Survey 5-year estimates) & 2015 \\
Owner-occupied housing unit rate & US Census Bureau (American Community Survey 5-year estimates) & 2015 \\
Vacant housing unit rate & US Census Bureau (American Community Survey 5-year estimates) & 2015 \\
Places of worship rate & Association of Religion Data Archives & 2010 \\
Mental health care providers rate & County Health Rankings \& Roadmaps & 2015 \\
Museum rate & Institute of Museum and Library Services & 2017 \\
K12 schools per 100,000 children & United States Geological Survey & 2016 \\
Percent active voter & State Board of Electors & 2016 \\
Percent area occupied by park & State Geographic Information Systems Data Portals \\
Nonprofit organizations rates & Urban Institute National Center for Charitable Statistics Data Archives \\
School-aged population & US Census Bureau & Various \\
County boundaries & United States Geological Survey & 2005 \\
\hline
\end{tabular}

${ }^{\mathrm{a}}$ Tweet counts were collected by the research team and are not included here. Nonprofits were broken down into National Taxonomy of Exempt Entities classes for analysis, but these classes are not shown here. Rates per 100,000 total population unless otherwise noted.

During analysis, we decided to test whether our results might be driven by inclusion of one county-Washington, DC_-because this county appeared to be an outlier for several reasons. For example, while its museums and other community amenities are very high, the population tends to be younger, and tweet counts were the highest. For this reason, we conducted a sensitivity analysis whereby the above model was also fitted without DC included. However, our incident rate ratios (IRRs) changed $<1 \%$ for all independent variables (see Multimedia Appendix 1); therefore, these results are not included here. All subsequent analyses included all 245 counties. All analyses were conducted using Stata v11 (StataCorp, College Station, TX, USA).

\section{Evaluation of Community Characteristics by Tweeting Index Values}

The suite of community characteristics outlined previously was selected due to each factor's potential role in promoting or hindering support, in-person treatment, opportunities for social interaction, or indicators of active community residents. We calculated means of each characteristic by TIV. We then calculated a ratio of TIV 5:1 and a Pearson correlation coefficient $(r)$ and $P$ value.

\section{Results}

Mapping captured \#MyDepressionLooksLike tweets revealed that most counties in the study region were not using the hashtag during the observation period (Figure 1). Most tweets were in urban environments (eg, New York City and Washington, DC). Many counties near the eastern seaboard had higher numbers of tweets than counties farther inland. Delaware and Vermont each had only one county with a captured tweet.

Maryland, New York, and Pennsylvania had the highest tweet counts in our study region. However, their statewide means showed they were similar to other states. Washington, DC was an outlier in descriptive statistics of counties by state (Multimedia Appendix 2), having higher percentages of single-person households, people living below the poverty line, females, and population aged 15-44 years. New Hampshire had the lowest average percentage of single-person households (mean 15), while Connecticut had the lowest average percentage living below the poverty line (mean 9). Average county percentages of female population were similar across all states. Maine had the lowest average percentage population aged 15-44 years (mean 35). Washington, DC had the lowest percentage of white population $(241,892 / 601,723,40 \%)$, and Maine and Vermont had the highest average percentages of white population (mean 96).

We found a positive, statistically significant correlation between several independent variables and tweet count (Table 2). These variables included percent population aged 15-44 years (IRR=1.11, $P=.02)$, female $\quad(\mathrm{IRR}=1.70, \quad P<.001)$, and single-person households (IRR=0.90, $P=.03$ ). Percentages white and below poverty level were not statistically significant (Table 2). Regression model residuals were then used to create TIVs, which showed lower than expected tweets (TIV 1) in eastern seaboard areas and expected values (TIV 2) in western inland areas (Figure 2). Communities tweeting more than expected were generally scattered across our study region, with the exception of a cluster in the northern seaboard area. 
Seeking to understand the relationship between the built environment and the levels of tweeting to connect about depression, we assembled a suite of community characteristics and related them to TIVs. We observed a $U$-shaped relationship between our TIVs and many of our community factors (see Table 3): rates of K12 schools, vacant housing, museums, places of worship, vacant housing rates, and health nonprofits. Almost all factors exhibiting $U$ patterns also exhibited statistically significant correlations with TIV. In other words, areas with both undertweeting and overtweeting correlated with lower rates of these community characteristics. One exception was percent active voters, whereby lower values for TIV (undertweeting) correlated with higher rates of active voters. We also observed an upward gradient between TIV and rates of many types of nonprofits including all, human services, public benefit, religion, and education. Specifically, lower rates of nonprofits correlated with undertweeting and higher rates correlated with overtweeting.

Figure 1. \#MyDepressionLooksLike tweets by county for 11 states and the District of Columbia (2016).

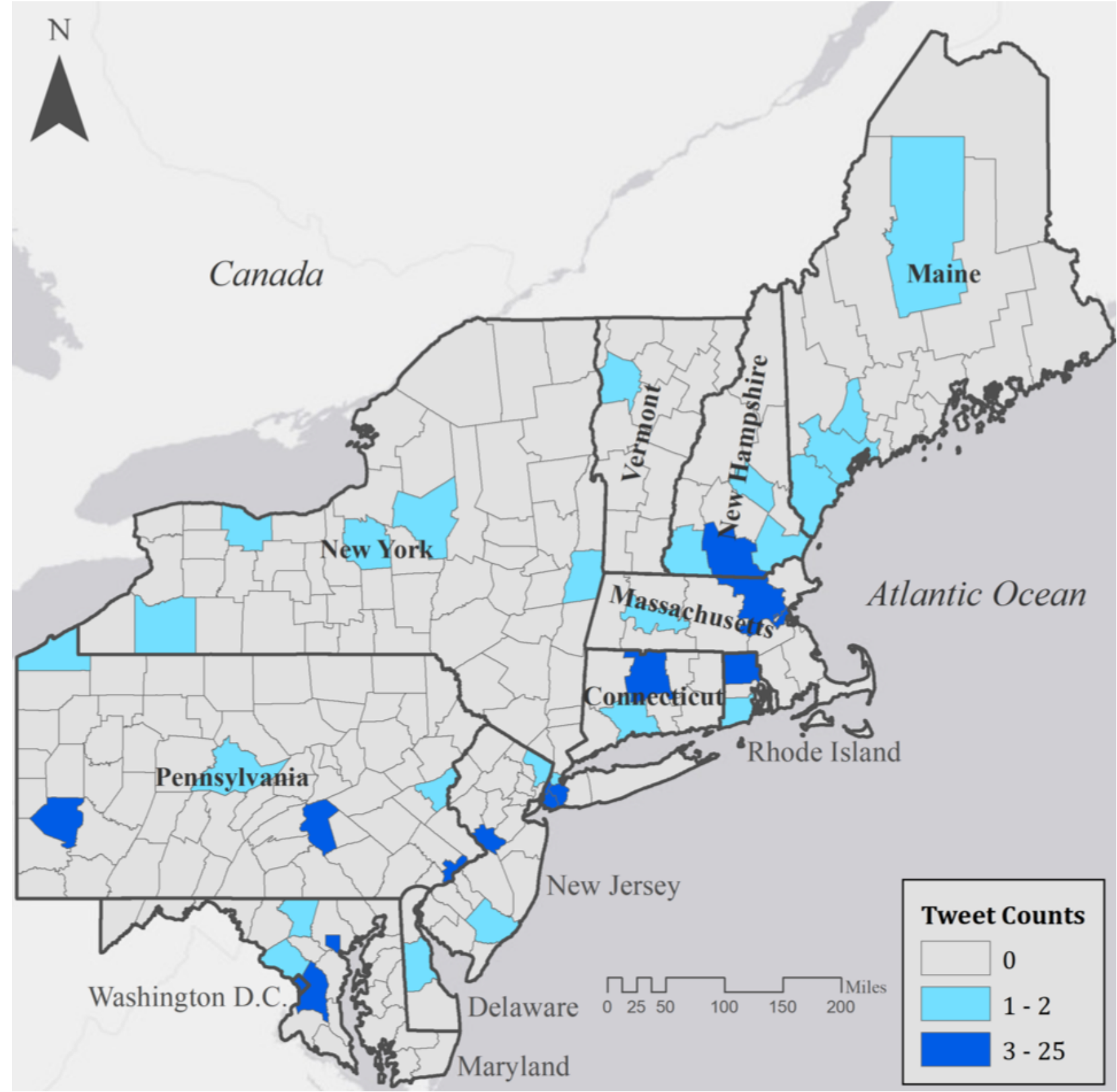


Table 2. Regression results used to calculate tweeting index values $(n=245)$ for counties in the study region.

\begin{tabular}{|c|c|c|c|}
\hline Independent variables & Incident rate ratio & $P$ value & $95 \% \mathrm{CI}$ \\
\hline Percent aged $15-44$ years & 1.11 & .02 & $1.02-1.21$ \\
\hline Percent female & 1.70 & $<.001$ & $1.25-2.29$ \\
\hline Percent white population & 0.99 & .37 & $0.96-1.02$ \\
\hline Percent single-person household & 0.90 & .03 & 0.82-0.99 \\
\hline Percent below poverty level & 1.05 & .31 & $0.95-1.16$ \\
\hline
\end{tabular}

Figure 2. Tweeting index values by county for 11 states and the District of Columbia. TIV: Tweeting index values.

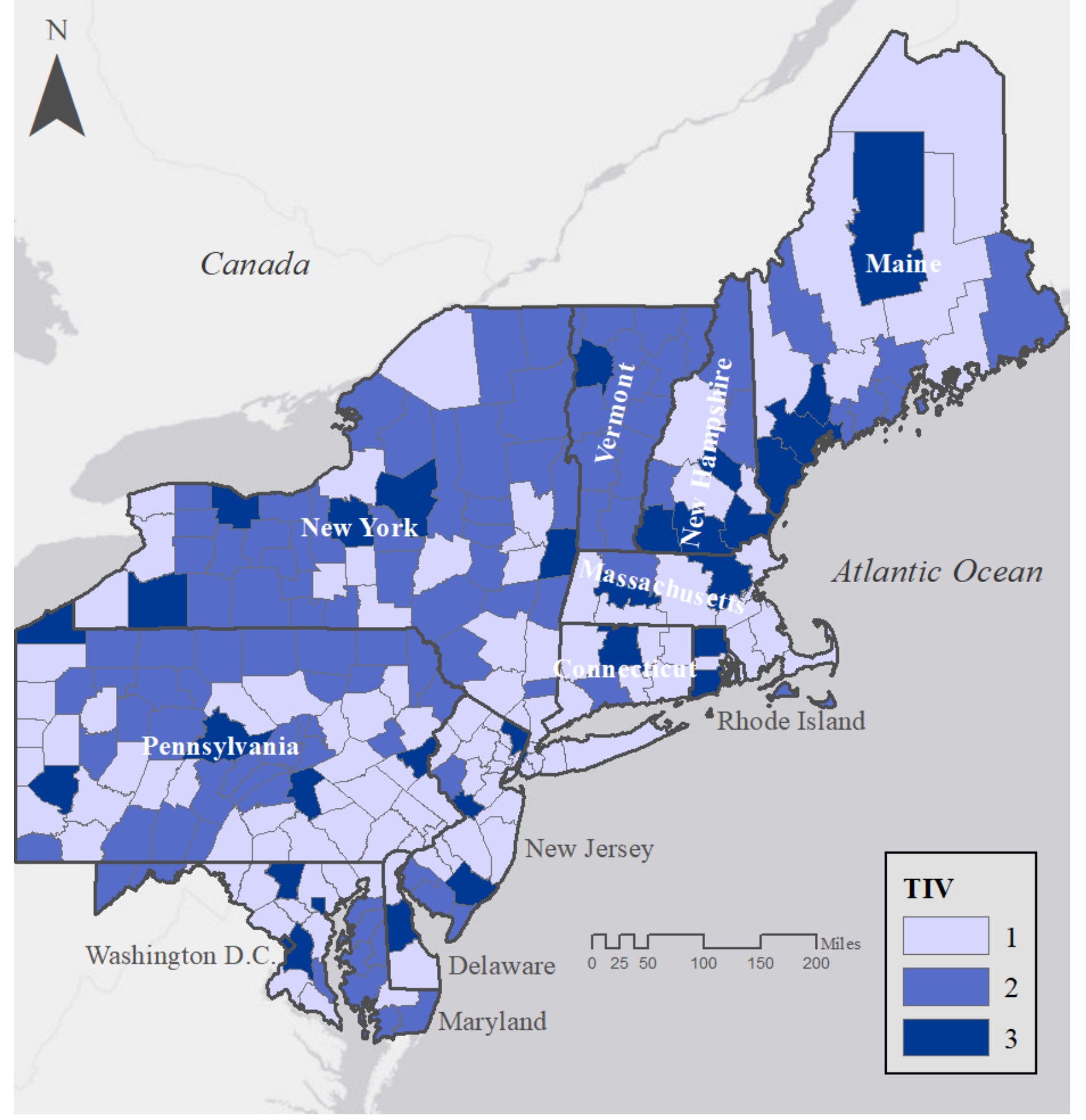


Table 3. Community characteristics by tweeting index values.

\begin{tabular}{|c|c|c|c|c|c|c|}
\hline Community characteristics & $\operatorname{TIV}^{\mathrm{a}} 1^{\mathrm{b}}$ & $\operatorname{TIV} 2^{\mathrm{b}}$ & $\operatorname{TIV}^{\mathrm{c}}$ & TIV3:TIV1 & $r$ & $P$ value \\
\hline K12 schools per 100,000 children, mean & 199 & 289 & 212 & 1.07 & 0.19 & .004 \\
\hline Museums rate, mean ${ }^{\mathrm{d}}$ & 17 & 33 & 20 & 1.18 & 0.20 & .002 \\
\hline Percent area occupied by park, mean & 9 & 9 & 10 & 1.11 & 0.04 & .49 \\
\hline Places of worship, mean ${ }^{\mathrm{d}}$ & 104 & 177 & 93 & 0.89 & 0.16 & .01 \\
\hline Vacant housing rate, mean ${ }^{\mathrm{d}, \mathrm{e}}$ & 6 & 17 & 7 & 1.17 & 0.16 & .01 \\
\hline Owner-occupied housing rate, mean ${ }^{\mathrm{d}, \mathrm{e}}$ & 26 & 29 & 25 & 0.96 & 0.08 & .21 \\
\hline Percent active voter, mean & 76 & 72 & 74 & 0.97 & -0.15 & .02 \\
\hline Mental health care providers rate, mean ${ }^{\mathrm{d}}$ & 209 & 157 & 293 & 1.40 & 0.09 & .18 \\
\hline Nonprofits (all) rate, mean ${ }^{\mathrm{d}}$ & 412 & 527 & 579 & 1.41 & 0.23 & $<.001$ \\
\hline Nonprofits (health) rate, mean ${ }^{\mathrm{d}}$ & 70 & 91 & 84 & 1.20 & 0.15 & .017 \\
\hline Nonprofits (human services) rate, mean ${ }^{\mathrm{d}}$ & 147 & 184 & 195 & 1.33 & 0.23 & $<.001$ \\
\hline Nonprofits (public or societal benefit) rate, mean ${ }^{\mathrm{d}}$ & 41 & 50 & 80 & 1.95 & 0.24 & $<.001$ \\
\hline Nonprofits (religious) rate, mean ${ }^{\mathrm{d}}$ & 12 & 14 & 17 & 1.42 & 0.13 & .04 \\
\hline Nonprofits (education) rate, mean ${ }^{\mathrm{d}}$ & 76 & 85 & 97 & 1.28 & 0.13 & .04 \\
\hline
\end{tabular}

aTV: tweeting index values.

${ }^{\mathrm{b}}$ Undertweeting.

${ }^{\mathrm{c}}$ Overtweeting.

${ }^{\mathrm{d}}$ Rate per 100,000 people.

${ }^{\mathrm{e}}$ Values in thousands.

\section{Discussion}

\section{Principal Findings}

Most prior research on use of Twitter to connect about depression focused on interpersonal variables. This research focusing on community factors uniquely contributes to the literature. In this study, three positive, statistically significant associations were found to predict the count of tweets from people connecting about depression, including percent female, percent population aged 15-44 years, and percent single-person households. These findings correspond with other studies showing higher rates of depression among women and single-person households [18]. The percent female correlation further suggests that women experiencing depression are turning to Twitter at higher rates than men although previous research has shown no difference in general Twitter use between men and women [30].

While we found several significant associations, some anticipated predictors of tweet counts were not confirmed. Percent below poverty level and percent white were not significantly associated with tweet counts. Our insignificant findings for area-level poverty contrast with some published data showing an association between poverty and depression [31]. On the other hand, our findings echo those from Cutrona et al, whereby other neighborhood factors, such as social disorder, were more influential than poverty [16]. Prior results on depression and race have been inconsistent, with some studies indicating that the built environment may be more relevant to depression than race composition [32]. Other studies indicate that perceived discrimination, social support, and coping may play a role in the relationship between race and depression [33].

In examining community characteristics related to overtweeting or undertweeting, rates of K12 schools, museums, places of worship, vacant housing rates, and health nonprofits exhibited a $U$ - shaped gradient across TIVs. Although Kaplan and Yen claim it difficult to illustrate a relationship between depression and lack of amenities, fewer amenities have been associated with higher depression rates within a neighborhood in prior research [34]. Our study reflected these difficulties because several community characteristics had a $U$ - shaped relationship with TIVs. However, the rates of several types of nonprofits showed a clear, upward trend with TIVs, similar to other studies [17]. Lack of neighborhood amenities, such as community-building nonprofits, may not only be associated with higher rates of depression, but may also lead to lower levels of connecting about depression in Web-based communities. This suggests that Web-based communities, rather than replacing physical connection, act as complements and proxies for nonvirtual social communities. In other words, if communities have abundant nonprofit organizations serving the public, thereby improving community participation, residents experiencing depression may be more likely to connect about depression on the Web [35]. Conversely, if a community is lacking these amenities, the isolation that residents feel may transfer to their Web-based presence [16]. 
This paper expanded the literature about depression in relation to Twitter by exploring and providing information about community characteristics that correlate with people turning to a Web-based community to connect about depression. Before this study, literature about depression relating to Twitter mainly consisted of how to interpret depression based on tweets and why people tweet about their mental health issues, such as depression. This included findings underlying the positive impact of Web-based platforms such as Twitter in discussing mental health issues, but also pointed to social media use and adverse consequences, including increased depressive symptoms. While often overlooked, people's environment strongly impacts the state of their mental health [36,37]. This study provided insight into aspects of a person's environment, for instance, living in an area with many nonprofits, which may have encouraged Twitter use to bolster social connections.

\section{Limitations}

Our study has several limitations. First, future research could expand the study area beyond the northeastern United States. As seen from Park et al's 2013 study in South Korea, people from all over the world use Twitter to seek connections, so understanding their physical communities may also lend insight into the research question. Future studies could also expand the time frame from which tweets were gathered. Increasing the time frame for capturing data would allow this paper to have greater population validity and allow for inferences about how neighborhood changes relate to depression. Because of our limited spatiotemporal scope and use of NCapture, our sample size was smaller than originally anticipated, thus presenting generalizability concerns. Additionally, we used the geotagged location to characterize the community of Twitter users; this partially limited our sample and may have introduced error. Geotags may not be representative of the Twitter user's community; rather, they could indicate places users were traveling to temporarily. Additionally, we used counties as a proxy for "community" since existing community-level data is often reported at the county level. In the future, we suggest a smaller geographic scale such as a city or town because these units are usually more representative of a person's community.

\section{Conclusion}

Our study is one of the first to explore built and social environmental contributions to the use of Twitter to connect about depression. Communities that overtweet and undertweet were more likely to have lower rates of K12 schools, museums, places of worship, vacant housing rates, and health nonprofits. These communities were also likely to have higher rates of active voters. Especially evident in our study is that communities with higher rates of nonprofits exhibited higher than expected levels of tweeting-suggesting that lack of community investment may influence Web-based connection seeking. Urban planning efforts may usefully promote amenities to bolster social interactions and lessen isolation, thus ultimately offering opportunities for social support for depression.

\section{Acknowledgments}

This study was funded by Michigan State University's Provost Undergraduate Research Initiative. We would like to thank Josh Vertalka, Katherine Bogen, Heather McCauley, and Amanda Rzotkiewicz for their contributions to the research process.

\section{Conflicts of Interest}

None declared.

\section{Multimedia Appendix 1}

Tables used for sensitivity analysis.

[PDF File (Adobe PDF File), 39KB-Multimedia Appendix 1]

\section{Multimedia Appendix 2}

Descriptive statistics for counties in study region by state.

\section{[PDF File (Adobe PDF File), 28KB-Multimedia Appendix 2]}

\section{References}

1. Internet Live Stats. 2017. Twitter Usage Statistics URL: http://www.internetlivestats.com/twitter-statistics/ [accessed 2017-11-28] [WebCite Cache ID 6vJcKjj3H]

2. Lachmar EM, Wittenborn AK, Bogen KW, McCauley HL. \#MyDepressionLooksLike: Examining Public Discourse About Depression on Twitter. JMIR Mental Health 2017 Oct 18;4(4):e43 [FREE Full text] [doi: 10.2196/mental.8141] [Medline: 29046270]

3. Kessler RC, Berglund P, Demler O, Jin R, Koretz D, Merikangas KR, et al. The epidemiology of major depressive disorder: results from the National Comorbidity Survey Replication (NCS-R). JAMA 2003 Jun 18;289(23):3095-3105. [doi: 10.1001/jama.289.23.3095] [Medline: 12813115]

4. Clement S, Schauman O, Graham T, Maggioni F, Evans-Lacko S, Bezborodovs N, et al. What is the impact of mental health-related stigma on help-seeking? A systematic review of quantitative and qualitative studies. Psychological Medicine 2015 Jan;45(1):11-27. [doi: 10.1017/S0033291714000129] [Medline: 24569086] 
5. Barney LJ, Griffiths KM, Jorm AF, Christensen H. Stigma about depression and its impact on help-seeking intentions. Australian \& New Zealand Journal of Psychiatry 2006 Jan;40(1):51-54. [doi: 10.1111/j.1440-1614.2006.01741.x] [Medline: $\underline{16403038]}$

6. Wang Y, Kraut RE, Levine JM. Eliciting and receiving online support: using computer-aided content analysis to examine the dynamics of online social support. J Med Internet Res 2015;17(4):e99 [FREE Full text] [doi: 10.2196/jmir.3558] [Medline: 25896033]

7. Diagnostic and Statistical Manual of Mental Disorders, Fifth Edition. Arlington, VA: American Psychological Association; 2013.

8. Mowery D, Smith HA, Cheney T, Bryan C, Conway M. Identifying Depression-Related Tweets from Twitter for Public Health Monitoring. Online Journal of Public Health Informatics 2016 Mar 24;8(1). [doi: 10.5210/ojphi.v8i1.6561]

9. Berry N, Lobban F, Belousov M, Emsley R, Nenadic G, Bucci S. \#WhyWeTweetMH: Understanding Why People Use Twitter to Discuss Mental Health Problems. J Med Internet Res 2017 Apr 05;19(4):e107 [FREE Full text] [doi: 10.2196/jmir.6173] [Medline: 28381392]

10. Park M, Cha C, Cha M. Depressive moods of users portrayed in Twitter. 2012 Presented at: Proceedings of the ACM SIGKDD Workshop on healthcare informatics (HI-KDD); 2012; Beijing, China.

11. Park M, McDonald DW, Cha M. Perception Differences between the Depressed and Non-Depressed Users in Twitter. ICWSM 2013;9:217-226.

12. Fox J, Moreland J. The dark side of social networking sites: An exploration of the relational and psychological stressors associated with Facebook use and affordances. Computers in Human Behavior 2015 Apr;45:168-176 [FREE Full text]

13. Chou HG, Edge N. "They are happier and having better lives than I am": the impact of using Facebook on perceptions of others' lives. Cyberpsychol Behav Soc Netw 2012 Feb;15(2):117-121. [doi: 10.1089/cyber.2011.0324] [Medline: 22165917]

14. Primack BA, Shensa A, Sidani JE, Whaite EO, Lin LY, Rosen D, et al. Social Media Use and Perceived Social Isolation Among Young Adults in the U.S. Am J Prev Med 2017 Feb 24. [doi: 10.1016/j.amepre.2017.01.010] [Medline: 28279545]

15. Davila J, Hershenberg R, Feinstein BA, Gorman K, Bhatia V, Starr LR. Frequency and Quality of Social Networking Among Young Adults: Associations With Depressive Symptoms, Rumination, and Corumination. Psychol Pop Media Cult 2012 Apr 1;1(2):72-86 [FREE Full text] [doi: 10.1037/a0027512] [Medline: 24490122]

16. Cutrona CE, Wallace G, Wesner KA. Neighborhood Characteristics and Depression: An Examination of Stress Processes. Curr Dir Psychol Sci 2006 Aug;15(4):188-192 [FREE Full text] [doi: 10.1111/j.1467-8721.2006.00433.x] [Medline: $\underline{18185846]}$

17. Latkin CA, Curry AD. Stressful neighborhoods and depression: a prospective study of the impact of neighborhood disorder. J Health Soc Behav 2003 Mar;44(1):34-44. [Medline: 12751309]

18. Weich S, Blanchard M, Prince M, Burton E, Erens B, Sproston K. Mental health and the built environment: cross-sectional survey of individual and contextual risk factors for depression. Br J Psychiatry 2002 May;180:428-433 [FREE Full text] [Medline: 11983640]

19. Twitter. Twitter Developers. 2017. Consuming streaming data URL: https://developer.twitter.com/en/docs/tutorials/ consuming-streaming-data.html[WebCite Cache ID 6vJcWivIv]

20. United States Census Bureau, 2010 Census.: United States Census Bureau; 2010. URL: https://www.census.gov/[WebCite Cache ID 70WEQcPeQ]

21. 2011-2015 ACS 5-year Estimates.: United States Census Bureau; 2015. URL: https://www.census.gov/data.html [accessed 2018-09-18] [WebCite Cache ID 72XTY7AmT]

22. Saraceno B, Levav I, Kohn R. The public mental health significance of research on socio-economic factors in schizophrenia and major depression. World Psychiatry 2005 Oct;4(3):181-185 [FREE Full text] [Medline: 16633546]

23. Kessler RC. Epidemiology of women and depression. J Affect Disord 2003 Mar;74(1):5-13. [Medline: 12646294]

24. Cairney J, Boyle M, Offord DR, Racine Y. Stress, social support and depression in single and married mothers. Soc Psychiatry Psychiatr Epidemiol 2003 Aug;38(8):442-449. [doi: 10.1007/s00127-003-0661-0] [Medline: 12910340]

25. Nolen-Hoeksema S. Sex differences in unipolar depression: evidence and theory. Psychol Bull 1987 Mar;101(2):259-282. [Medline: $\underline{3562707]}$

26. Mental Health Information: Major Depression.: National Institute of Mental Health URL: https://www.nimh.nih.gov/health/ statistics/major-depression.shtml[WebCite Cache ID 70WDpoFnL]

27. Pratt LA, Brody DJ. Depression in the United States household population, 2005-2006. NCHS Data Brief 2008 Sep(7):1-8 [FREE Full text] [Medline: 19389321]

28. Pearlin LI, Johnson JS. Marital status, life-strains and depression. Am Sociol Rev 1977 Oct;42(5):704-715. [Medline: 931191]

29. Arc GP. 5. Redlands, CARI. Version 10 URL: https://arcgis.com

30. Social Media Fact Sheet. 2018. URL: http://www.pewinternet.org/fact-sheet/social-media/,[WebCite Cache ID 70WE399dM]

31. Belle D, Doucet J. Poverty, Inequality, And Discrimination As Sources Of Depression Among U.S. Women. Psychology of Women Quarterly 2003 May 6;27(2):101-113. 
32. Mair C, Diez RAV, Galea S. Are neighbourhood characteristics associated with depressive symptoms? A review of evidence. J Epidemiol Community Health 2008 Nov;62(11):940-6, 8 p following 946. [doi: 10.1136/jech.2007.066605] [Medline: $\underline{18775943]}$

33. Noh S, Kaspar V. Perceived discrimination and depression: moderating effects of coping, acculturation, and ethnic support. Am J Public Health 2003 Feb;93(2):232-238. [Medline: 12554575]

34. Yen IH, Kaplan GA. Poverty area residence and changes in depression and perceived health status: evidence from the Alameda County Study. International journal of epidemiology 1999;28(1):90-94. [Medline: 9807543]

35. Brusilovskly E, Townley G, Snethen G, Salzer MS. Social Media Use, Community Participation and Psychological Well-Being Among Individuals with Serious Mental Illness. Computers in Human Behavior 2016:232-240.

36. Evans GW. The built environment and mental health. J Urban Health 2003 Dec;80(4):536-555 [FREE Full text] [doi: 10.1093/jurban/jtg063] [Medline: 14709704]

37. Galea S, Ahern J, Rudenstine S, Wallace Z, Vlahov D. Urban built environment and depression: a multilevel analysis. J Epidemiol Community Health 2005 Oct;59(10):822-827 [FREE Full text] [doi: 10.1136/jech.2005.033084] [Medline: $\underline{16166352]}$

\title{
Abbreviations \\ IRR: incident rate ratio \\ TIV: tweeting index value
}

\author{
Edited by A Tsanas; submitted 29.11.17; peer-reviewed by J Colditz, N Berry; comments to author 31.01.18; revised version received \\ 28.06.18; accepted 24.07.18; published 05.11.18 \\ Please cite as: \\ DeJohn AD, Schulz EE, Pearson AL, Lachmar EM, Wittenborn AK \\ Identifying and Understanding Communities Using Twitter to Connect About Depression: Cross-Sectional Study \\ JMIR Ment Health 2018;5(4):e61 \\ URL: http://mental.jmir.org/2018/4/e61/ \\ doi: $10.2196 /$ mental.9533 \\ PMID: $\underline{30401662}$
}

(C)Amber D DeJohn, Emily English Schulz, Amber L Pearson, E Megan Lachmar, Andrea K Wittenborn. Originally published in JMIR Mental Health (http://mental.jmir.org), 05.11.2018. This is an open-access article distributed under the terms of the Creative Commons Attribution License (https://creativecommons.org/licenses/by/4.0/), which permits unrestricted use, distribution, and reproduction in any medium, provided the original work, first published in JMIR Mental Health, is properly cited. The complete bibliographic information, a link to the original publication on http://mental.jmir.org/, as well as this copyright and license information must be included. 